\title{
A critical analysis of Peru's HIV grant proposals to the Global Fund
}

Carlos F. Cáceres ${ }^{\mathrm{a}^{*}}$, Ana B. Amaya ${ }^{\mathrm{a}, \mathrm{b}^{*}}$, Clara Sandoval ${ }^{\mathrm{a}}$, and Rocío Valverde ${ }^{\mathrm{a}}$

anstitute of Health, Sexuality and Human Development, Cayetano Heredia University, Lima, Peru; ${ }^{b}$ London School of Hygiene and Tropical Medicine, London, UK

* Both authors contributed equally to this work.

Corresponding authors. Email: Carlos.caceres@upch.pe, ana.amaya@1shtm.ac.uk 
Peru has applied to six of the Global Fund to Fight AIDS, Tuberculosis and Malaria (the Global Fund) rounds for funding, achieving success on four occasions. The process of proposal development has, however, been criticised, especially concerning the use of evidence, relevance/consistency, and performance indicators.

We aimed to analyse the Peruvian Global Fund proposals according to those dimensions, providing feedback to improve future local efforts and inform global discussions around Global Fund procedures. We analysed the content of four HIV-focused proposals (rounds 2, 5, 6 and 8) regarding epidemic context, needs identification and prioritisation, and monitoring and evaluation systems.

Peruvian proposals submitted after round 1 were described as resulting from collaborative inputs involving formerly unrepresented sectors, principally 'vulnerable populations'. However, difficulties arose regarding the amount and quality of evidence about the epidemiological context; limited consideration of social determinants of the epidemic; lack of theory-driven interventions and little synergy across projects; and the inclusion of weak monitoring and evaluation systems, with poor indicators and measurement procedures.

Prioritising the development of analytical and technical skills to generate Global Fund proposals would enhance the country's capacity to produce and utilise evidence, improve the technical-political interface, strengthen information systems, and lead to more informed decisionmaking and accountability. 
Keywords: HIV; health policy; Global Fund; proposal analysis; evaluation

\section{Introduction}

Despite having a relatively stable, concentrated HIV epidemic and a prevalence of $0.4 \%$ among adults (Joint United Nations Programme on HIV/AIDS [UNAIDS] \& World Health Organization [WHO], 2009), Peru is one of the Latin American countries that has most actively sought and received funding from the Global Fund to Fight AIDS, Tuberculosis and Malaria (the Global Fund) for those three diseases (Cáceres \& Mendoza, 2009).

Since the first time Peru applied for a grant, in 2002, there have been significant changes in terms of Global Fund proposal requirements. Initially, proposals were submitted using a flexible format, evolving over time into fixed formats with very detailed contextual, administrative, and political information (Buse \& Harmer, 2007).

HIV/AIDS proposal elaboration processes have undergone different phases in Peru. The unsuccessful proposal for round 1 (which was not available and does not form part of this analysis) was formulated independently by the Ministry of Health. This proposal was followed by three consecutive, successful proposals (rounds 2, 5, and 6) and another unsuccessful proposal submitted for round 8. A new proposal submitted for round 10 under the special provision for key populations has recently been approved but was also not part of this analysis. The proposal approved for the 10th round (for US\$12.5 million) in 2011 brought the total amount for HIV/AIDS activities by the Global Fund to approximately US\$90 million (Global Fund, 2010). Table 1 presents a brief description of the four proposals that served as a basis for this study. 
Table 1. Description of Global Fund proposals ${ }^{\star}$

\begin{tabular}{|c|l|l|c|l|}
\hline Round & \multicolumn{1}{|c|}{ Proposal name } & Reference framework & Period & Funding level \\
\hline $\mathbf{2}$ & $\begin{array}{l}\text { Strengthening prevention } \\
\text { and control of AIDS in } \\
\text { Peru }\end{array}$ & $\begin{array}{l}\text { National consensus-building } \\
\text { process }\end{array}$ & $2004-2008$ & $\begin{array}{l}\text { US } \$ 21,347,134 \\
\text { Successful }\end{array}$ \\
\hline $\mathbf{5}$ & $\begin{array}{l}\text { Closing gaps to achieve the } \\
\text { Millennium Development } \\
\text { Goals for HIV/AIDS in } \\
\text { Peru }\end{array}$ & $\begin{array}{l}\text { National consensus-building } \\
\text { process }\end{array}$ & $2006-2010$ & $\begin{array}{l}\text { US } \$ 12,867,465 \\
\text { Successful }\end{array}$ \\
\hline $\mathbf{6}$ & $\begin{array}{l}\text { National multisectoral } \\
\text { plans: Integrating resources } \\
\text { for the fight against } \\
\text { HIV/AIDS in Peru }\end{array}$ & Multisectoral strategic plan & $2007-2011$ & $\begin{array}{l}\text { US } \$ 32,669,809 \\
\text { Successful }\end{array}$ \\
\hline $\mathbf{8}$ & $\begin{array}{l}\text { Making a difference: } \\
\text { consolidating a broad and } \\
\text { integral response to HIV } \\
\text { and Tuberculosis in Peru }\end{array}$ & Multisectoral strategic plan & $2009-2013$ & $\begin{array}{l}\text { US\$72,775,647 (for } \\
\text { both diseases) } \\
\text { Unsuccessful }\end{array}$ \\
\hline
\end{tabular}

*Round 10 approved and did not form part of this analysis

Source: Peru-Grant Portfolio-The Global Fund to Fight AIDS, Tuberculosis and Malaria. Online. Retrieved from http://portfolio.theglobalfund.org/en/Country/Index/PER

In line with Global Fund regulations, these proposals were developed by the Country Coordinating Mechanism (named Coordinadora Nacional Multisectorial en Salud CONAMUSA), which included participants from several sectors of the government, civil society, and international aid agencies. The second-round proposal (second RP) was seen as a collaborative effort that all sectors involved in the CONAMUSA participated in and that responded to the national priorities at the time (Sprungli, 2003). The fifth and sixth RPs, on the other hand, were linked to previous discussion processes; the fifth RP was related to the second RP, and the sixth RP was linked to the 2006-2011 National Multisectoral Plan for HIV/AIDS (CONAMUSA, 2005; CONAMUSA, 2006). CARE, an international NGO, was designated as the principal recipient of all of these grants. 
Proposal development is important because it provides the framework the country will follow to manage funding and achieve results. A 2006 independent assessment of Global Fund proposal development and review processes for the three diseases in seven countries (Wilkinson et al., 2006), including Peru, found that in the countries under study there was a need to improve communication and clarify Global Fund principles; improve country ownership, donor harmonisation, and alignment with national systems; strengthen and support the technical review process; and use technical assistance and partnerships to improve country proposal development processes. Moreover, while other studies have examined the content of proposals submitted to the Global Fund in other countries (Gurkin, 2011; Libatique, 2004; MACRO International, 2009; Mueller \& Hanson, 2005), this study is unique in that it specifically focuses on HIV proposal development in Peru within the 2002-2009 period in order to understand how country processes to develop Global Fund HIV proposals respond to local reality and needs. This analysis will allow for a discussion about both the national response to HIV/AIDS and the opportunities and limitations implied in the emergence of the Global Fund, which from a supranational level influences the scope and content of the countrylevel response to the epidemic. Furthermore, reviewing these documents and studying their formulation processes are also key steps to better understanding the strengths and weaknesses of broader ongoing activities (WHO \& UNAIDS, 2007).

\section{Methods}

This study had the following three objectives in examining proposals in a sequential manner: a) to assess how and to what extent the national proposals submitted to the Global Fund arose from a careful analysis of the national context of the HIV epidemic; b) to assess the consistency of activities and strategies included in the proposals with the expected effects, impacts, and outcomes, as well as determining if there is a logical link 
from one proposal to the other; c) to assess whether the proposals include the appropriate mechanisms for monitoring and evaluating impacts and outcomes. These three dimensions encompass the key technical aspects of a programmatic proposal, all of which should be evidence-based: background, goals and activities, and performance assessment. For each of these objectives, we formulated indicators intended to operationalise the key dimensions identified for analysis (see Table 2).

Table 2. Study objectives and indicators

\begin{tabular}{|c|c|}
\hline Objectives & Indicators \\
\hline $\begin{array}{l}\text { 1. Do the national proposals submitted to } \\
\text { the Global Fund arise from an } \\
\text { assessment of the national HIV/AIDS } \\
\text { situation, identifying and prioritising } \\
\text { intervention needs? }\end{array}$ & $\begin{array}{ll}\text { - } & \text { Published references } \\
\text { - } & \text { Contextualised citations } \\
\text {. } & \text { Updated, time-specific figures } \\
\text {. } & \text { Statements supported by data } \\
\text { Consistency of data interpretation across } \\
\text { proposals }\end{array}$ \\
\hline $\begin{array}{l}\text { 2. Are the activities and strategies included } \\
\text { in the proposals consistent with the } \\
\text { expected effects, impacts, and } \\
\text { outcomes? Is there a logical link from } \\
\text { one proposal to the other? }\end{array}$ & $\begin{array}{l}\text { Appropriate intervention models, supported by } \\
\text { evidence } \\
\text { Appropriate adaptation, if possible, validated } \\
\text {. } \\
\text { Interventions aligned with a problem } \\
\text { Continuity and synergy with other plans and } \\
\text { projects, particularly previous Global Fund } \\
\text { grants and official national strategies }\end{array}$ \\
\hline $\begin{array}{l}\text { 3. Do the proposals include appropriate } \\
\text { mechanisms for verifying impacts and } \\
\text { outcomes? Are the impacts and } \\
\text { outcomes of the projects monitored and } \\
\text { evaluated based on a system that } \\
\text { provides timely estimates of such } \\
\text { indicators? }\end{array}$ & $\begin{array}{l}\text { Indicators already existing in the system, rather } \\
\text { than 'ad hoc' } \\
\text { Clearly formulated indicators } \\
\text { To the extent possible, internationally } \\
\text { recognised indicators } \\
\text { Clear, parsimonious processes to identify targets }\end{array}$ \\
\hline
\end{tabular}

To do this, we conducted content analysis of the official texts of four HIV/AIDS proposals submitted to the Global Fund for rounds 2, 5, 6, and 8. We also reviewed the 2007-2011 Multisectoral Strategic Plan since it served as a reference framework for the last two proposals. A team of four researchers reviewed the documents, identifying emerging themes and assigning codes according to the objectives. Recurring themes were then charted and agreed upon in order to later interpret them and identify relationships between them. These interpretations were also contrasted with a document 
review.

This document review was conducted by searching grey literature and peerreviewed articles addressing Global Fund proposals and results in Peru and other countries between 2002 and 2013, using the keywords 'proposal', 'evaluation', 'grants', 'HIV', and 'Global Fund' in the databases Embase, PubMed, LILACS, and Google Scholar. Finally, conclusions and recommendations were developed to improve future Global Fund specific procedures, with potential implications for other similar mechanisms of international aid in the future.

\section{Study limitations}

This study has limitations such as the difficulty in defining a single, detailed evaluation framework across different proposals in an evolving context; restrictions in assessing the context where each of these proposals were developed and discussed; and variations in project design and implementation. Nevertheless, researchers' proximity to the projects and the realities they try to address was an advantage given the prior knowledge of how the proposals were developed. Finally, this analysis is intended to generate lessons for the future, and not serve as an evaluation of processes or actors involved in the past.

\section{Findings and discussion}

We have subdivided our results into three major sections: evidence base of the proposals, consistency and appropriateness of the proposed interventions, and inclusion of appropriate monitoring and evaluation systems.

\section{Evidence base of the proposals}

We examined the extent to which these proposals used substantive, high-quality 
evidence, and whether the evidence led to a coherent, well-supported assessment that allowed for the identification and prioritisation of key interventions. The emerging themes centered around two basic issues: how the epidemic was characterised and how population sizes were estimated.

\section{Characterisation of the epidemic}

Content analysis revealed that the scope and depth of information about the epidemic used in the proposals had improved over time, partly due to more rigorous requirements and more standardised submission formats in recent years. For example, in the eighth RP, the HIV epidemic in Peru is described in greater detail as an epidemic concentrated on men who have sex with men (MSM), relying on the most recent prevalence estimates from sentinel surveillance for pregnant women and at-risk populations, following UNAIDS criteria. This description is much more systematic and complete than formulations in the initial proposals (CONAMUSA, 2002) and illustrates improvements facilitated by the Global Fund through improved guidelines. At the same time, however, an arbitrary, inconsistent interpretation of the same evidence becomes apparent according to the intended project focus. The statement below, which suggests imminent feminisation, provides an example of this since the male-female ratio had become stable in 1997 at 3:1, with similar characteristics to today's epidemic (i.e., low prevalence in the general population, high prevalence among MSM):

\footnotetext{
'The epidemic in Peru, as in the rest of the world, has shifted towards younger populations and women. Because of this, the male: female ratio of cases has shifted from 27/1 in 1987 to 2.6/1 in March of 2005, confirming the biological and social vulnerability of the female population (p. 35, fifth RP)'.
}

Interestingly, the same variation in the male/female ratio is more accurately summarised 
in the sixth RP (Section 4.4.2, sixth RP), which states that this ratio had remained around 3:1 for over 8 years, thus suggesting stabilisation (Cáceres \& Mendoza, 2009). Regarding MSM, while high figures are described, no effort is made to explain the low stability of HIV prevalence estimates over time that is presented in the fifth RP using data from sentinel surveillance studies (i.e., $18 \%$ in $1998,11 \%$ in 2000 , and $13.9 \%$ in 2002). It can be argued that such considerable variation had to be explained based on the characteristics of the cross-sectional surveillance operations using recruiter-based convenience sampling. The proposal only states that this average figure hides substantial heterogeneities across different regions of the country. However, other heterogeneities such as the several sub-populations included under the MSM label, including transgender and gay populations, as well as those involved in sex work, are not mentioned.

In fact, while the term MSM was considered representative for an especially complex vulnerable group (where differences across sub-groups were ignored), by the time the sixth and eighth RPs were developed, several studies had shown evidence of other sub-populations with social characteristics that were misrepresented within a generic MSM category. This was the case not only with the transgender population but also of sex worker sub-populations (Hwahng \& Nuttbrock, 2007; Cáceres, Konda, Pecheny, Chatterjee, \& Lyeria, 2006). Nevertheless, the term MSM was maintained in the last two proposals, and such generalisation delayed consideration of specific interventions targeting sub-populations, which would have improved the strategies in place.

Finally, a consistent finding is that the term 'vulnerability', while widely used to identify pre-defined groups such as MSM, prison inmates, sex workers and young people, rarely results in an analysis of the conditions leading to greater social 
vulnerability which have been identified in prior studies to increase risk of exposure to infection (Gupta, Parkhurst, Ogden, Aggleton, \& Mahal, 2008; Auerbach, Parkhurst, \& Cáceres, 2011).

\section{Population-size estimates}

A problem encountered during the elaboration of the proposals has been the apparent lack of updated data from the Ministry of Health. Interestingly, the proposals do not show recent data from official sources such as the Epidemiology Bureau, choosing instead to use data from other sources such as UNAIDS or expert estimates. This results in inconsistencies, especially when dealing with population sizes across proposals.

Regarding people living with HIV/AIDS (PLHA), the number of PLHA is calculated using two different approaches: a) a count based on cumulative case reports and b) estimates of the total number of PLHA. These approaches are inconsistently alternated throughout the submissions. For example, the second RP describes 12,000 reported AIDS cases and an estimated 5000 unreported or unnotified cases, without providing a source for these numbers. Moreover, within this same proposal it is reported that around 7000 HIV cases were eligible to start antiretroviral (ARV) treatment but only $10 \%$ of them were actually receiving it. These were unofficial estimates, since no formal study of ARV coverage and needs had been conducted at the time (p. 32, second RP). While in part these inconsistencies reflect an evolving field of population-size estimation, they also suggest the need for additional standardisation so internationally available statistics, for example, are used by default.

Moreover, the same data was frequently interpreted in a different manner in consecutive proposals. For example, the sixth RP used the same estimate of people in need of treatment that was reported in the second RP, although this time a $90 \%$ 
coverage rate was reported (section 4.4.2, sixth RP), disregarding the appropriateness of pointing out any growth or decrease in cases during that period. This suggests that analysis of new proposals requires the consideration of the overall previous or ongoing Global Fund support to the country. This need was in part resolved by the Global Fund with a policy of integration of interrelated grants (Global Fund, 2011). Finally, these proposals lack any reference to PLHA morbidity and survival, either, which would be important in assessing the need for specific services for PLHA, particularly regarding access to services.

Concerning 'vulnerable groups', population-size estimates for these groups do not appear until the eighth RP, which used data from the 2008 Universal Access Report, reached through expert consensus. Here MSM and female sex worker (FSW) population-size assumptions, together with their HIV prevalence estimates, were used to approximate the number of HIV-infected MSM and FSW as 20,214 and 644, respectively (section 4.2.1 and 4.2.2, eighth RP). Moreover, figures for pregnant women were taken from aggregate data from the Ministry of Health in order to calculate HIVscreening coverage among pregnant women, the proportion of positive results, and prophylaxis coverage of HIV-positive pregnant women and their offspring, without discussing how appropriate this combination of sources might or might not be.

In summary, proposals had generally characterised the epidemic by using epidemiological data in an inconsistent, poorly documented manner, without further interpretation. Poor intervention justification often derives from a lack of available, recent data. Clearly, this is a serious problem not only for Peru but in most lower- and middle-income countries (Waltham \& Sahay, 2006; Fraser et al., 2005) and represents a serious limitation to the potential effectiveness of the Global Fund mechanism. While the Global Fund submission process requires proposals to be supported by evidence in 
order to justify actions (Kerkhoff \& Szlezak, 2006), it is critical to ensure the functioning of a sentinel surveillance system that regularly collects data from pregnant women, MSM (divided into subcategories such as gay/lesbian and transgender), sex workers, and prisoners (Cáceres, Mendoza, Konda, \& Lescano, 2007). Moreover, although social, economic, and cultural data were included, this information was presented separately and did not fully contextualise or explain the quantitative data.

\section{Consistency and appropriateness of proposed interventions}

The main emerging themes regarding the consistency between interventions were related to internal (i.e., across proposal components) and external consistency (i.e., across proposals and with other policies and plans). We analysed these two areas in relation to their implications for the various populations affected by the epidemic and for the general population.

\section{General population}

Goals and activities aimed at prevention in the general population, including youth, focused on promoting safe sexual practices, managing STIs, increasing risk awareness, and preventing vertical transmission. The two major strategies framed for young people are the sex-education initiative (in the second RP) and syndromic management for STIs (in the fifth and sixth RPs), with the eighth RP including both approaches. In general, no effort was made to present subsequent proposals as a continued, complementary effort. Rather they were presented as external to each other. 
The sexuality-education components targeting youths and adolescents, included in the second and eighth RPs, mention the inclusion of a formal sex-education component in the current curriculum for adolescents attending public schools. In fact, a sex-education component was previously included in the curriculum in the 1990s, but its scope, as well as the pedagogic framework, has changed over time according to overall government policy. Education-sector strategies in the Global Fund proposals focused more specifically on promoting HIV education and condom use, through training of school teachers and the use of innovative strategies such as training peer promoters. However, these strategies did not seem to depart from an analysis of the status of sex education in the school system, and they were operationally, rather than conceptually, linked to sex education. It must be said, though, that clear guidance on how to best integrate HIV education in schools was not provided by international technical cooperation agencies, in part due to contrasting political views about sex education during the 2000s. Furthermore, the UNESCO sexuality-education guide was published only until 2009 (UNESCO, 2009).

Training health professionals is a priority in all of the proposals and centres on STI syndromic management and care. The weight assigned to STI prevention and care suggests that these are key strategies to preventing HIV within the general population and in specific groups; however, such presumption is not clearly stated and the strategy is proposed without supporting references for its importance or even STI rates in the general population. For example, we know that women's risk for infection is highly dependent on their male partner's sexual behaviors, and even monogamous women in Peru have been found to be part of large sexual networks (Johnson, Alarcon, \& Watts, 2003). 
Strategies to combat stigma and discrimination, included in the second and fifth RP, were not delineated within a clear conceptual framework, nor did these activities consider how this issue had been addressed within other contexts. For instance, studies have found little evidence to suggest that the predominant HIV stigma-reduction strategies (among these, the provision of information at the individual level and through mass-media campaigns) have led to significant changes in the population's sexual behavior (Mahajan et al., 2008). It is also the case that interventions designed to reduce stigma have limited impact if not coupled with comprehensive programmes to scale up treatment and care services (Maman et al., 2009), making the case for targeting the structural determinants of stigma.

Furthermore, based on a study conducted in five African countries, Holzemer, Uys, and Makoae (2007) developed a conceptual framework modelling the dynamics of HIV stigma. This model describes the context in which stigma occurs as one that can be divided into the environment, the health care system, and the agent, suggesting activities to manage each of these. Along those lines, the final evaluation of the fifth RP explains that while there was an improvement in the attitude of the general population toward PLHA, the same improvements have not fully reached health care institutions and schools, primarily concerning vulnerable populations (Cáceres et al., 2012).

Prevention of mother-to-child transmission (PMTCT) was also present in all proposals, and they focused on (a) increasing coverage for HIV screening during prenatal care (or delivery in the case of pregnant women who did not receive pre-natal care) and (b) offering access to PMTCT. Formulation of the coverage activity reflected legal changes during the decade (i.e., HIV screening became mandatory in 2004), while the latter activity reflected evolving models of PMTCT over time. However, projects generally failed to ensure appropriate follow-up of children perinatally exposed to HIV, 
primarily due to problems estimating perinatal transmission rates due to informationsystem weaknesses (CARE Peru, 2009).

\section{'Vulnerable' populations}

Interventions focused on 'vulnerable populations' (i.e., MSM and female sex workers) across all proposals have continuously relied on a combination of peer outreach and regular medical check-ups, focusing on STI screening and treatment as well as voluntary HIV counselling and testing (VCT). Although this combination has been in place since the 1990s, and community involvement is a proven practice to ensure participation (UNAIDS, 2005), the proposals lacked any analysis of the effectiveness of this approach or its impact on MSM. Furthermore, a study conducted by CARE found that peer promoters were frequently perceived just as recruiters who brought their peers to medical check-ups, neglecting their educational role (CARE Peru, 2009). The medical component of the model was positive in its concern for offering a safe, nondiscriminatory environment to traditionally marginalised populations, although the predominant concept of care seemed to reflect the traditional paradigm of controlling HIV spread through sex workers, where the main focus is placed on preventing outcasts from spreading diseases (Evans \& Lambert, 2008).

\section{People living with HIV/AIDS (PLHA)}

All four proposals included actions targeting PLHAs, which have generally diversified over time. The second RP included funding to start up a national HIV treatment programme (with a commitment from the government to assume treatment costs after year 2) and establish laboratory-based monitoring, as well as improve provider training and develop comprehensive care for PLHA, although what comprehensive care entails 
was not defined. After the second RP, proposed activities diversified to replace the importance-of-treatment provision, which was state-funded then. New actions included some clearly relevant additions such as improving care for TB/HIV co-infection (added in the eighth RP), as well as activities that were not supported by evidence and lacked basic implementation criteria. An example of this was promoting care and services for orphans and children whose mothers were living with HIV, despite their being few in number and despite the fact that they were never clearly identified and mapped. Treatment for opportunistic infections was included in the fifth RP, but with limited duration and coverage.

Given the participation of PLHA in the CONAMUSA, they had the opportunity to be vocal during proposal development, and their request for the inclusion of peer counsellors and family support was appropriately expressed in the second RP, as well as in workshops included in the fifth RP. The latter proposal also included micro-finance loans, although this activity was not rooted in a careful assessment given the literature available on the strengths and weaknesses of such initiatives (Dworkin \& Blankenship, 2009; Caldas et al., 2010), and may explain the numerous implementation issues experienced early on (Caceres et al., 2012). In the eighth RP, special attention was paid to PLHA sub-groups with increased vulnerability (such as sex workers, transgender persons, adolescents, and prison inmates) by means of joint work and efforts involving PLHA grassroots organisations and health facilities. In synthesis, while many of the proposed activities were relevant over time, starting with the creation of the national treatment programme, these activities rarely emerged from a comprehensive monitoring of PLHA needs and did not necessarily reflect a well-thought-out, comprehensive strategy, but instead a juxtaposition of numerous activities of varying relevance and feasibility. 


\section{Development of a favorable environment}

The development of a favourable socio-political environment for overall HIV/AIDS activities was addressed in the National Multisectoral Strategic Plan through several of its objectives. Objective 7 aimed to promote a favourable political, social, and legal environment with a human rights perspective and with the participation of the most vulnerable communities (MSM, FSW, and prisoners) and PLHA (Ministerio de Salud del Peru [MINSA], 2007). Objective 8, on the other hand, proposed ensuring a comprehensive and coordinated multisectoral response regarding the development of joint activities for the prevention and control of STIs and HIV/AIDS. The latter strategic objective aimed to strengthen information systems and ensure monitoring and evaluation to enable timely decision-making processes and measurement of goals (MINSA, 2007).

The second RP proposed advocacy campaigns to strengthen CONAMUSA; whereas the fifth RP proposed a communication campaign to prevent discrimination against PLHA, workshops to improve health workers' and schoolteachers' attitudes, and activities to strengthen PLHA organisations. The sixth RP addressed the relationship between the government and civil society, promoting the formation of intersectoral committees to ensure budgetary allocations to implement the STI and HIV/AIDS plans, the integration of an information system, and timely decision-making about HIV/AIDS policies.

In summary, most of the HIV response strategies in the proposals were riskcentered. Very few specific actions were aimed at reversing the vulnerability of affected populations or addressing major determinants of such conditions, other than some media-based campaigns aiming to sensitise the general population to HIV-related 
stigma. The approach that has prevailed for managing risk and vulnerability has mainly focused on the individual, regardless of whether it was directed toward key populations or the general population. Moreover, the approach primarily focused on medical care, behavioural change, and STI syndromic care, replicating the traditional public heath approaches with a biomedical and clinical view of health (Castro, 2003).

It is important to highlight that these proposals' aims were not the result of comprehensive, systematic discussions about the epidemic and its evolution in Peru, given prior interventions (including preceding Global Fund grants). As explained above, nearly all of the evidence presented in the second, fifth, and sixth RPs derives from studies conducted in 2002, making it difficult to argue across proposals or clearly account for the success of ongoing activities to justify the need for continued, complementary actions. Moreover, given that most of the activities proposed corresponded to the 2007-2011 Multisectoral Strategic Plan objectives, it could be argued that both the plan and the proposals responded to the same few unchecked strategies developed over a decade before. This has been found in prior studies (Brugha et al., 2004; Kapilashrami \& McPake, 2012; Libatique, 2004) where proposals seemingly state facts to support the country's view rather than the other way around. Additionally, while there were opportunities for synergies or complementarity in actions that involved scaling up, unfortunately, most of the proposed activities were external to each other.

\section{Inclusion of an appropriate monitoring and evaluation system}

This section addresses the existence of a monitoring and evaluation (M\&E) system built into the proposal, which relies on sensible impact and outcome indicators and is based on an up-to-date information system. We focused on the second RP M\&E procedures, 
given that subsequent proposals followed the same model, and we provide additional comments for the other proposals.

The five higher-level indicators presented in the second RP represent indicators to measure both impacts and effects. These five indicators were: (1) proportion of HIVpositive MSM; (2) proportion of HIV-positive female sex workers; (3) proportion of HIV-positive pregnant women; (4) proportion of infants of HIV-positive mothers who do not serorevert by 18 months of age; and (5) proportion of PLHA accessing comprehensive care.

Four of the five indicators mentioned required the use of biological markers of infection as impact indicators, while the indicator on comprehensive care coverage can be considered an effect indicator. In addition to impact/effect indicators, a number of outcome indicators for specific activities were included. These included, for example, providing information on infection prevention and condom use to youth and most-atrisk populations; coverage of prophylaxis to prevent vertical transmission; and coverage of and adherence to ARV treatment.

At the same time, the first three indicators measure HIV prevalence, and their use as impact indicators has become inappropriate over time given that this figure represents both new and existing cases within a context of increasing access to antiretroviral treatment, where prevalence is expected to increase due to longer survival rates among those infected. This limitation was unknown in 2002 since treatment scaleup was just in its infancy; therefore, use of these indicators was appropriate for the second RP. However, subsequent proposals continued to use the same indicators or modifications of unknown feasibility such as use of HIV incidence among MSM (fifth $\mathrm{RP})$, thus failing to address increasingly clear evaluation problems in previous proposals. 
This evaluation framework presented a number of limitations that restricted the observation of impacts and effects. Not only were indicators frequently inappropriate to estimate positive change (as described above), but targets were not based on a thorough analysis of realistic change according to trends, as was the case for prevalence targets among FSW and pregnant women (for whom targets of maximum prevalence did not represent a challenge as they had already been reached at baseline). Targets for condom use for populations such as adolescents and prison inmates were also unrealistic in the proposed time frame (e.g., increases of up to 100\%). The representativeness of other indicators was also problematic, where the use of pre-natal care data to measure HIV testing coverage among pregnant women was of limited utility given the still moderate coverage of pre-natal care during 2002 to 2003 (MINSA, 2006). This problem could have been avoided by reviewing the literature on achievable targets of change for specific interventions according to their baseline levels.

Finally, the proposals had two major, persistent shortcomings: a) an overall evaluation design built into the project was lacking, affecting the likelihood that data collection would follow the same procedures in each phase and would facilitate the comparability and validity of results; and b) indicators proposed in most cases did not rely on an existing, reliable information system, and no provision was made to develop such a system, even in subsequent proposals submitted when such problems were already apparent (CARE Peru, 2009). Across proposals, major difficulties included the following: a) a lack of standardised methods of measuring indicators and b) a lack of provisions to improve the capacity and commitment of the Ministry of Health regarding the timely collection of reliable indicators. Eventually, when projects were implemented, this implied the need to employ ad hoc surveys and other secondary 
sources to fill this gap in information. These issues were also found in the principal recipients' summative evaluation of the second RP (CARE Peru, 2009).

\section{Conclusion}

This study sought to analyse the content of the four HIV-focused proposals submitted by Peru to the Global Fund from 2002 to 2009 in order to assess if the evidence presented in the proposals was accurate and reliable and allowed for adequate assessment, identification, and prioritisation of interventions; whether the four proposals showed relevance and internal and external consistency; and finally, if appropriate monitoring and evaluation mechanisms were proposed.

Key findings show that the evolution of Global Fund proposal requirements has translated into greater rigor in presenting evidence, yet this has been limited by a weak information system that does not provide the tools to respond to changes in the epidemic. While prior Global Fund grants have sought to improve these information systems, the multiplicity of reporting mechanisms and lack of training among health workers need to be addressed to effectively plan and implement activities. Moreover, the concentrated nature of the Peruvian epidemic requires targeted interventions that go beyond the traditional MSM grouping, including transgender populations, for example. Besides targeted interventions, the Ministry of Health should also focus on proposing comprehensive policies that include other sectors in order to address the root causes of vulnerability in order to tackle the drivers that perpetuate the increased exposure of these populations to HIV. The lack of consistency across proposals has hindered efforts that at times seemed disjointed from existing policies, such as in the case of sexuality education. This may in part be explained by the turnover and lack of long-term, stable policy-makers, which has been found to be an important factor affecting continuity and 
scale-up of actions (Balabanova et al., 2013). Promoting continuity among civil servants despite political shifts would be one way to respond to this problem, as well as ensuring that the main stakeholders are trained in relevant HIV policies.

This study has also shown a number of limitations in Peru that go beyond the proposals of the Global Fund, such as clear deficiencies in the surveillance system of the HIV/AIDS epidemic or in the selection of interventions to respond to it. The country should use this and other studies, including internal project evaluations, to improve their capacity in terms of proposal design, implementation, and evaluation. This analysis does not imply, however, that the Peruvian HIV projects funded by the Global Fund have been ineffective. On the contrary, a recent summative evaluation has shown that the second, fifth, and sixth RP have played a positive, useful role in such response, and they represent an important example of collaboration between the state and civil society to confront a major social problem (Universidad Peruana Cayetano Heredia, 2013). This leads us to suggest that while good projects can be implemented in problematic ways, projects with limitations can also find solutions for such shortcomings as they are being implemented.

Two questions may be posed for the ongoing discussion about the opportunities presented by the Global Fund, considering that funding will significantly decrease: 1) Should the Global Fund make additional efforts to ensure the quality of proposals through the direct provision of technical assistance although it has consistently sustained that it is only a funding mechanism and such assistance should be primarily provided by partners active in the country (Wilkinson et al., 2006)? 2) Given that other studies have found that current decision-making processes may favour political negotiations over technical consistency (Libatique, 2004), should the pre-eminence of 
local political agreement be maintained, or should other mechanisms be found to strengthen the relative weight of technical consistency and efficiency?

Finally, to ensure that positive results are obtained and targets are reached in Global Fund projects, particularly in a time of fiscal constraints, it seems clear that greater effort should be placed on setting activities based on improved epidemiological data and available evidence of intervention effectiveness. Moreover, heightening technical quality, allowing for flexibility to correct inappropriate indicators or targets as identified during implementation, and setting precise monitoring and evaluation frameworks and procedures within the proposals submitted for funding, would greatly strengthen future proposals. These limitations we identified here are likely to be present in many other proposals from countries receiving aid from the Global Fund, reminding us of the need to improve information systems and to accurately set targets in lowerand middle-income countries, and, at the level of the Global Fund, to substantially improve proposal evaluation. The extraordinary opportunity still offered by the Global Fund to curb the pandemic must not be missed.

\section{Funding and acknowledgements}

We are grateful to AHPSR/WHO, who funded this study, as well as Ximena Salazar and Alfonso Silva Santisteban for their useful comments on an earlier version of this manuscript. 


\section{References}

Auerbach, J., Parkhurst, J., \& Cáceres, C. (2011). Addressing social drivers of HIV/AIDS for the long-term response: Conceptual and methodological considerations. Global Public Health, 6, S293-309.

Balabanova, D., Mills, A., Leasing, C., Akkazieva, B., Banteyerga, H., Dash, U., ... McKee, M. (2013). Good health at low cost 25 years on: Lessons for the future of health systems strengthening. The Lancet, 381, 2118-2133.

Brugha, R., Donoghue, M., Starling, M., Ndubani, P., Ssengooba, F., Fernandes, B., \& Walt, G. (2004). The Global Fund: Managing great expectations. The Lancet, 364, 95 100 .

Buse, K., \& Harmer, A.(2007). Seven habits of highly effective global public-private health partnerships: Practice and potential. Social Science and Medicine, 64, 259-271.

Cáceres, C., Konda, K., Pecheny, M., Chatterjee, A., \& Lyeria, R. (2006). Estimating the number of men who have sex with men in low and middle income countries.

Sexually Transmitted Infections, 82, iii3-iii9.

Cáceres, C., \& Mendoza, W. (2009). The national response to the HIV/AIDS epidemic in Peru: Accomplishments and gaps - a review. Journal of Acquired Immune Deficiency Syndromes, 51, S60-S66.

Cáceres, C., Mendoza, W., Konda, K., \& Lescano, A. (2007). Nuevas evidencias para las políticas y programas de salud en VIH/SIDA e infecciones de transmisión sexual en el Perú: Información disponible hasta febrero 2007. Lima: UPCH and PAHO/WHO.

Cáceres, C., Salazar, V., Smith, E., Salazar, X., Sandoval, C., Navarro, M., \& Anamaria, P. (2012). Informe de medicion de indicadores y evaluacion final: programa en VIH de V ronda. Lima: Coordinadora Nacional Multisectorial en Salud.

Caldas, A., Arteaga, F., Munoz, M., Zeladita, J., Albujar, M., Bayona, J., \& Shin, S. (2010). Microfinance: A general overview and implications for impoverished individuals living with HIV/AIDS. Journal of Health Care for the Poor and Underserved, 21, 986-1005.

CARE Peru. (2009). Evaluación final del componente VIH y sida del programa de segunda ronda financiado por el Fondo Mundial: Fortalecimiento de la prevención y control del VIH y sida en el Perú. Lima: CARE Peru. 
Castro, A. (2003, April). Determinantes Socio-políticos de la Infección por VIH: violencia estructural y culpabilización de la víctima. Paper presented at Second Latin American AIDS Forum, Habana.

Coordinadora Nacional Multisectorial en Salud. (2002). Fortalecimiento de la prevencion y control del SIDA y la Tuberculosis en el Perú. Retrieved from The Global Fund to Fight AIDS, Tuberculosis and Malaria:

http://portfolio.theglobalfund.org/en/Grant/Index/PER-202-G01-H-00

Coordinadora Nacional Multisectorial en Salud. (2005). Cerrando brechas: Hacia el logro de los objetivos de desarrollo del Milenio en TB y VIH/SIDA en el Perú. Propuesta con enfoque de descentralización multisectorial participativa. Retrieved from The Global Fund to Fight AIDS, Tuberculosis and Malaria: http://portfolio.theglobalfund.org/en/Grant/Index/PER-506-G03-H

Coordinadora Nacional Multisectorial en Salud. (2006). Planes nacionales multisectoriales: Integrando recursos para la lucha contra el VIH/SIDA y la TB en el Peru. Retrieved from The Global Fund to Fight AIDS, Tuberculosis and Malaria: http://portfolio.theglobalfund.org/en/Grant/Index/PER-607-G05-H

Dworkin, S., \& Blankenship, K. (2009). Microfinance and HIV/AIDS prevention: Assessing its promise and limitations. AIDS and Behavior, 13, 462-469.

Evans, C., \& Lambert, H. (2008). The limits of behaviour change theory: Condom use and contexts of HIV risk in the Kolkata sex industry. Culture, Health and Sexuality, 10, $27-41$.

Fraser, H., Blondich, P., Destine, M., Choi, S., Mamlin, B., \& Szolovits, P. (2005). Implementing electronic medical record systems in developing countries. Informatics in Primary Care, 13, 83-96.

Global Fund to Fight AIDS, Tuberculosis and Malaria. (2010). Global Fund disbursements by region, country and grant agreement. Geneva: The Global Fund to Fight AIDS, Tuberculosis and Malaria.

Global Fund to Fight AIDS, Tuberculosis and Malaria. (2011). Comprehensive funding policy and related board decisions. Geneva: The Global Fund to Fight AIDS, Tuberculosis and Malaria.

Gupta, G., Parkhurst, J., Ogden, J., Aggleton, P., \& Mahal, A. (2008). Structural approaches to HIV prevention. The Lancet, 372, 764-775. 
Gurkin, A. (2011). Analysis of rounds 8, 9 and 10 Global Fund HIV proposals in relation to men who have sex with men, transgender people and sex workers. Geneva: The Global Fund to Fight AIDS, Tuberculosis and Malaria.

Holzemer, W., Uys, L., Makoae, L. (2007). A conceptual model of HIV/AIDS stigma from five African countries. Journal of Advanced Nursing, 58, 541-551.

Hwahng, S., \& Nuttbrock, L. (2007). Sex workers, fem queens, and cross-dressers: Differential marginalizations and HIV vulnerabilities among three ethnocultural maleto-female transgender communities in New York City. Sexuality Research \& Social Policy, 4, 36-59.

Johnson, K., Alarcon, J., \& Watts, D. (2003). Sexual networks of pregnant women with and without HIV infection. AIDS, 17, 605-612.

Kapilashrami, A., \& McPake, B. (2012). Transforming governance or reinforcing hierarchies and competition: Examining the public and hidden transcripts of the Global Fund and HIV in India. Health Policy and Planning, 28, 626-635.

Kerkhoff, L., \& Szlezak, N. (2006). Linking local knowledge with global action: Examining the Global Fund to Fight AIDS, Tuberculosis and Malaria through a knowledge system lens. Bulletin of the World Health Organization, 84, 629-635.

Libatique, R. C. (2004). Global Fund proposal development-a Philippines experience. Brighton: International HIV/AIDS Alliance.

MACRO International. (2009). The five-year evaluation of the Global Fund to fight AIDS, Tuberculosis and Malaria: Synthesis of study areas 1, 2 and 3. Geneva: MACRO International.

Mahajan, A., Sayles, J., Patel, V., Remien, R. H., Sawires, S. R., Ortiz, D. J., ... Coates, T. J. (2008). Stigma in the HIV/AIDS epidemic: A review of the literature and recommendations for the way forward. AIDS, 22, S67-79.

Maman, S., Abler, L., Parker, L., Lane, T., Chirowodza, A., Ntogwisangu, J., ... Fritz, K. (2009). A comparison of HIV stigma and discrimination in five international sites: The influence of care and treatment resources in high prevalence settings. Social Science and Medicine, 68, 2271-2278.

Ministerio de Salud del Peru. (2006). Avanzando hacia una maternidad segura en el Perú: Derecho de todas las mujeres. Lima: Ministerio de Salud del Peru. 
Ministerio de Salud del Peru. (2007). Plan Estrategico Multisectorial 2007-2011 para la prevencion y control de las ITS y VIH/SIDA en el Peru. Retrieved from

CONAMUSA-Coordinadora Nacional Multisectorial en Salud:

http://www.conamusa.org.pe/normas.htm

Mueller, D., \& Hanson, K. (2005). Analysis of malaria proposals submitted to the Global Fund to Fight AIDS, Tuberculosis and Malaria (GFATM), round 1-4:

Recommendations for round 5 Proposals. London: Roll Back Malaria Partnership.

Sprungli, M. (2003). La confianza como capacidad de participar democraticamente en una experiencia multisectorial: Caso CONAMUSA. Lima: KALLPA Association.

UNAIDS. (2005). Expanding access to HIV treatment through community-based organizations: A joint publication of Sidaction, the Joint United Nations Programme on HIVIAIDS (UNAIDS) and the World Health Organization (WHO). UNAIDS best practice collection. Geneva: UNAIDS.

UNAIDS, \& World Health Organization. (2009). Epidemiological fact sheet on HIV and AIDS: Core data on epidemiology and response. Peru 2008. Geneva: UNAIDS.

UNESCO. (2009). International technical guidance on sexuality education: An evidence-informed approach for schools, teachers and health educators. Paris: UNESCO.

Universidad Peruana Cayetano Heredia. (2013). Evaluación final del programa intervención en VIH de VI Ronda: Planes estratégicos multisectoriales - integrando recursos para la lucha contra el VIH/SIDA en el Perú. Lima: Universidad Peruana Cayetano Heredia.

Waltham, G., \& Sahay, S. (2006). Research on information systems in developing countries: Current landscape and future prospects. Information Technology for Development, 12, 7-24.

Wilkinson, D., Brugha, R., Hewitt, S., Trap, B., Eriksen, J., Nielsen, L., Weber, W. (2006). Assessment of the proposal development and review process of the Global Fund to Fight AIDS, Tuberculosis and Malaria. Søborg: Euro Health Group.

World Health Organization \& UNAIDS. (2007). A framework for monitoring and evaluating HIV prevention programmes for most-at-risk populations. Geneva:

UNAIDS. 
